\title{
Lyotard e a pós-modernidade
}

\section{Lyotard and post-modernity}

Cristiane Maria Marinho ${ }^{1}$

\section{Resumo}

Neste artigo será apresentada a categoria da pós-modernidade considerando os estudos realizados por Lyotard na sua obra $A$ condição pós-moderna. $O$ autor desenvolverá o conceito de pós-modernidade como descrença nos grandes relatos da modernidade e sua substituição pelos pequenos relatos, bem como a substituição do consenso próprio da modernidade pelo dissenso e pela paralogia características da pós-modernidade. Será feito também uma reflexão crítica e conclusiva sobre as fronteiras desse universo pós-moderno e o capital contemporâneo.

Palavras-chave: modernidade - pós-modernidade - capitalismo

\section{Abstract}

In this article the category of the post-modernity will be presented finding the studies carried out by Lyotard in his work The condition post-modern. The author will develop the concept of powders-modernity like disbelief in the great reports of the modernity and his substitution for the small reports, as well as the substitution of the own consensus of the modernity for the dissenso and it shears paralogia characteristics of the powders-modernity. Modern-powders and the contemporary capital will be done also a concluding reflection on the frontiers of this universe.

key words: modernity - post-modernity - capitalism

\section{INTRODUÇÃO}

No seu livro $A$ condição pós-moderna, Lyotard esclarece que 0 objeto de seu estudo é a situação do saber nas sociedades mais desenvolvidas, a qual decidiu chamar 'pós-moderna', palavra usada no continente americano pela sociologia e pela crítica e que designa a cultura após as transformações ocorridas em relação à crise dos grandes relatos e que afetaram as regras dos jogos da ciência, da literatura e das artes no final do século XIX.

A crise dos relatos inicia com a sua transformação em fábula pela ciência. Por não serem meramente instrumentais e buscarem a verdade, os 
relatos legitimam, no entanto, as suas próprias regras, transformando-se em filosofia e, com isso, se autolegitima como metadiscurso e passa a se chamar de ciência moderna. Daí, a suposição da racionalidade universal possibilitar o consenso acerca de um enunciado que contém um juízo verdadeiro, como, por exemplo, a paz universal proposta no projeto lluminista. O saber é legitimado por um 'metarrelato' que implica em uma filosofia da história com conceitos de justiça e verdade pré-determinados. O livro de Lyotard se propõe, precisamente, a desvendar os caminhos da deslegitimação das grandes narrativas modernas como passaremos a demonstrar.

\section{PÓS-MODERNIDADE: DESLEGITIMAÇÃO DOS GRANDES RELATOS DA MODERNIDADE.}

A pós-modernidade caracteriza-se justamente pela descrença nesses 'metarrelatos' relacionados à metafísica e a universidade e legitimados pelo progresso científico. A grande narrativa, portanto, se transforma em um simples universo lingüístico pragmático que não é, necessariamente, comunicável. Nas palavras de Lyotard:

\footnotetext{
considera-se 'pós-moderna' a incredulidade em relação aos 'metarrelatos'. E, sem dúvida, um efeito do progresso das ciências, mas este progresso, por sua vez, a supõe. Ao desuso do dispositivo metanarrativo de legitimacão corresponde sobretudo a crise da filosofia metafísica e a da instituição universitária que dela dependia (LYOTARD, 1993, p. 3). (Grifos nossos).
}

Na sociedade pós-moderna, sem a crença nas grandes narrativas, existe uma diversidade de jogos de linguagem, onde os que têm poder de decisão determinam que a vida só tenha por objetivo o aumento da eficácia. A vida fica reduzida ao aumento do poder e o papel da justiça social e da verdade científica é o de otimizar as performances e a eficácia do sistema. O critério da eficiência generaliza-se por todos os jogos da vida ${ }^{2}$

Lyotard pondera sobre o sentido da nova legitimidade do melhor desempenho diante da descrença das 'metanarrativas', refletindo que a 
condição pós-moderna não é somente um instrumento para o exercício do poder, mas ela traz uma possibilidade de refletirmos criticamente sobre a imprevisibilidade do real, contrária ao consenso conservador dos especialistas:

\begin{abstract}
A condição pós-moderna é, todavia, tão estranha ao desencanto como à positividade cega da deslegitimação. Após os 'metarrelatos', onde se poderá encontrar a legitimidade? O critério de operatividade é tecnológico; ele não é pertinente para se julgar o verdadeiro e o justo. Seria pelo consenso, obtido por discussão, como pensa Habermas? Isto violentaria a heterogeneidade dos jogos de linguagem. $E$ a invenção se faz sempre no dissentimento. O saber pós-moderno não é somente o instrumento dos poderes. Ele aguça nossa sensibilidade para as diferenças e reforça nossa capacidade de suportar o incomensurável. Ele mesmo não encontra sua razão de ser na homologia dos experts, mas na paralogia ${ }^{3}$ dos inventores (LYOTARD, 1993a, p. xvii).
\end{abstract}

A hipótese de trabalho de Lyotard "é a de que o saber muda de estatuto ao mesmo tempo em que as sociedades entram na idade dita pósindustrial e as culturas na idade dita pós-moderna" (LYOTARD, 1993, p. 3). Segundo o autor, não é fácil ter um quadro desse período, pois esta mudança social começou por volta do final dos anos 50 , época do fim da reconstrução da Europa, variando de país para país e de atividade para atividade. Dada essa imprecisão, Lyotard não parte de um quadro geral da época do surgimento do pós-moderno e sim de uma característica do seu objeto de estudo, o saber nas sociedades desenvolvidas e chama a atenção para o fato do saber científico ser somente mais uma espécie de discurso, dentro da visão deslegitimante das 'metanarrativas', bem como para o fato das ciências e das técnicas de vanguarda, nos últimos tempos, versarem sobre a linguagem.

Por isso há que se considerar a influência das informações tecnológicas e das máquinas informacionais sobre o saber, tanto na sua produção e pesquisa, quanto na sua transmissão. Essa transformação geral não deixará intacta a natureza do saber. Este "não pode se submeter aos novos canais, e tornar-se operacional, a não ser que o conhecimento possa ser traduzido em quantidades de informação" (Ibid., p. 4).

O conhecimento se apartará do sujeito cognoscente e, com isto, modificará o princípio da formação moderna (Bildung) que avaliava o saber como algo constitutivo do sujeito: 
Pode-se então esperar uma explosiva exteriorização do saber em relação ao sujeito que sabe [...], em qualquer ponto que este se encontre no processo de conhecimento. $\mathrm{O}$ antigo princípio segundo o qual a aquisição do saber é indissociável da formação (Bildung) do espírito, e mesmo da pessoa, cai e cairá cada vez mais em desuso (lbid., p. 4).

Outra modificação desse novo universo do saber é a sua transformação radical em valor como mera mercadoria. O saber terá como objetivo da sua produção, o mercado e a troca, tornando secundário o seu valor de uso. Nos últimos decênios, o saber se transformou na principal força de produção e elemento econômico decisivo das populações produtivas nos países desenvolvidos e sua ausência um ponto de estrangulamento para os países em desenvolvimento. Dessa forma,

$\mathrm{Na}$ idade pós-industrial e pós-moderna, a ciência conservará e sem dúvida reforçará ainda mais sua importância na disputa das capacidades produtivas dos Estados-nações. [...]. Sob a forma de mercadoria informacional indispensável ao poderio produtivo, o saber já é e será um desafio maior, talvez o mais importante, na competição mundial pelo poder. Do mesmo modo que os Estados-nações se bateram para dominar territórios, e com isto dominar o acesso e a exploração das matérias-primas e da mão-de-obra barata, é concebível que eles se batam no futuro para dominar as informações. Assim encontra-se aberto um novo campo para as estratégias industriais e comerciais e para as estratégias militares e políticas (Ibid., p. 4).

Agora, o que é decisivo na circulação de um conhecimento não é a sua capacidade de retirar alguém da ignorância e sim sua potencialidade de melhorar a performance e o desempenho de uma dada mão-de-obra para a melhoria do processo produtivo. Em outras palavras, para Lyotard houve uma mercantilização generalizada do saber.

A hipótese de trabalho de Lyotard, modificação do estatuto do saber na sociedade pós-industrial e cultura pós-moderna ou sociedade informatizada, não pretende ser original nem verdadeira, mas busca possibilitar a capacidade de discernimento sobre as sociedades informatizadas mais desenvolvidas, para iluminar certos aspectos da formação do saber e dos seus efeitos sobre o 
poder público e as instituições civis (Ibid., p. 11). Questiona, de forma radical, o progresso das ciências e das técnicas com seu correspondente crescimento econômico e desenvolvimento sócio-político e admitida a acumulação do saber técnico e científico, o máximo que se discute é a sua forma. Ademais, a crença na acumulação do saber científico é falaciosa, pois o saber científico não é "o" sinônimo de saber. Há uma outra importante espécie de saber que é o narrativo (lbid., p. 12).

O saber científico está intimamente ligado à legitimação compreendida como um processo pelo qual um legislador é autorizado a promulgar uma lei como norma ${ }^{4}$ :

O direito de decidir sobre o que é verdadeiro não é independente do direito de decidir sobre o que é justo, mesmo se os enunciados submetidos respectivamente a esta e àquela autoridade forem de natureza diferente. É que existe um entrosamento entre o gênero de linguagem que se chama ciência e o que se denomina ética e política: um e outro procedem de uma mesma perspectiva ou, se preferir, de uma mesma 'opção', e esta chama-se Ocidente (lbid., p. 12).

Dessa forma, pode-se afirmar que o estatuto atual do saber científico é de subordinação aos países poderosos, e com as novas tecnologias corre 0 risco ainda maior de transformar-se em um dos principais elementos de seus embates. Isso exige o exame apurado daquela dupla legitimação, que na sua forma mais originária evidencia saber e poder como uma só questão: "quem decide o que é saber, e quem sabe o que convém decidir? O problema do saber na idade da informática é mais do que nunca o problema do governo" (lbid., 13).

O referencial teórico-metodológico utilizado na investigação lyotardiana acerca do saber na sociedade pós-moderna é o pensamento de Wittgenstein com sua ênfase nos fatos de linguagem e seus aspectos pragmáticos (lbid., p. 15). Lyotard apóia-se no discurso wittgensteiniano que se centraliza nos efeitos dos discursos e nos diversos tipos de enunciados ou jogos de linguagem, os quais são determinados por regras específicas. Nos jogos de linguagem as regras não têm legitimação por elas próprias, mas por 
um acordo exterior a elas feito pelos jogadores. Se não há regra, não há jogo, sendo que qualquer modificação em uma regra existente modifica o jogo. Enfim, todo enunciado lingüístico é um lance no jogo ${ }^{5}$.

Dois princípios norteiam o procedimento metodológico na análise lyotardiana. O primeiro "é que falar é combater, no sentido de jogar, e que os atos de linguagem provêm de uma agonística geral" (Ibid., p. 17). Mesmo que não se jogue somente para ganhar, tem um gosto de luta o prazer da invenção de palavras novas e a criação de novos sentidos, que fazem a evolução da língua. O segundo princípio, fundamental e complementar ao primeiro, "é que o vínculo social observável é feito de 'lances' de linguagem” (ibid., p. 17).

$\mathrm{Na}$ leitura lyotardiana, a linguagem como vínculo social é uma alternativa pós-moderna. A Modernidade, diversamente, tinha outros parâmetros para a representação desse vínculo social. Dois exemplos significativos estão na representação social de dois modelos do final do século XIX, o Funcionalismo com sua harmonia social e o Marxismo com o princípio da luta de classes e a dialética (Ibid., p. 20).

Para entender o estado atual do saber nas sociedades industriais avançadas é preciso conhecer a sociedade na qual ele se insere. Dessa forma, pode-se afirmar que o rumo econômico na atual fase capitalista, mediante o desenvolvimento tecnológico, redefine o papel do Estado. Nessa sociedade contemporânea as decisões não caberão mais às classes políticas dirigentes e sim a especialistas que têm acesso aos autômatos, máquinas cibernéticas detentoras das mais importantes informações A economia agora largamente determinada pela tecnologia, muda as funções dos Estados, e isso exige novas alternativas sociais, as quais se distanciam do marxismo e do socialismo, tidos agora como superados. (Cf. (LYOTARD, 1993, p. 27).

O que tem de novo nesta realidade social é a recusa dos instrumentos políticos e coletivamente representativos tradicionais. Bem como a perda da referência dos grandes ideais. Dessa forma, 
com os heróis da história atual, se tornam difíceis. [...]. Pois não se trata verdadeiramente de uma finalidade de vida. Esta é deixada à diligência de cada cidadão. Cada qual é entregue a si mesmo. E cada qual sabe que este si mesmo é muito pouco (Ibid., p. 28).

Nesse âmbito, então, se dilui a idéia de coletividade, norteadora do período moderno, assomando em seu lugar o princípio individualista. Esse individualismo, surgido da decomposição das grandes narrativas modernas que tinham a referência de um ideal coletivo, não implica necessariamente, na obra de lyotard, em uma dissolução do vínculo social. É somente uma nova forma de vínculo social que por vezes é criticada mais por um sentimento de nostalgia:

\footnotetext{
Desta decomposição dos grandes Relatos, [...], segue-se o que alguns analisam como a dissolução do vínculo social e a passagem das coletividades sociais ao estado de uma massa composta de átomos individuais [...]. Isto não é relevante, é um caminho que nos parece obscurecido pela representação paradisíaca de uma sociedade 'orgânica' perdida (Ibid., p. 28).
}

Dessa forma, o átomo individual é pouco, mas não está sozinho, pois o tempo todo é atravessado por mensagens diferenciadas constitutivas de novos vínculos sociais ${ }^{6}$. Além do que, este 'si mesmo' não é um ser passivo, pois tem sempre um poder sobre essas mensagens que o atravessam: é remetente, destinatário ou referente. E seu deslocamento em meio aos jogos de linguagem é tolerado e suscitado pelo próprio sistema, com a finalidade de melhorar seu próprio desempenho como sistema.

$\mathrm{Na}$ análise lyotardiana, os jogos de linguagem foram propostos como método geral de conhecimento do saber na sociedade pós-moderna. A linguagem é o vínculo social nessa nova fase das sociedades desenvolvidas ${ }^{7}$ e assume um novo estatuto, tanto por que a comunicação nessa fase histórica tornou-se central, bem como porque a linguagem se diferencia da forma que tinha antes, na época moderna: nem manipula, nem simplesmente informa:

numa sociedade em que a componente comunicacional torna-se cada dia mais evidente, simultaneamente como realidade e como problema, é certo que o aspecto de linguagem [...] adquire uma nova importância, que seria superficial reduzir à alternativa tradicional da 
palavra manipuladora ou da transmissão unilateral de mensagem, por um lado, ou da livre expressão ou do diálogo, por outro (Ibid., p. 29).

$\mathrm{Na}$ teoria da comunicação contemporânea, as mensagens têm formas e efeitos diversos - são denotativas, prescritivas, avaliativas, performativas, etc. - e não funcionam apenas comunicando informação. Assim, "reduzi-las a esta função é adotar uma perspectiva que privilegia indevidamente o ponto de vista do sistema e seu único interesse. Pois é a máquina cibernética que funciona pela informação" (Ibid., p. 30). Há que se levar em consideração o aspecto agonístico da linguagem que não está presente na informática, mas que constitui o vínculo social alicerçado pela linguagem

A abordagem das instituições contemporâneas do saber deve seguir essa perspectiva da linguagem como vínculo social que não se limita somente a informar burocraticamente, mas que constitui um jogo de linguagem com seus elementos agonísticos: "O que é preciso para compreender desta maneira as relações sociais, em qualquer escala [...], não é somente uma teoria da comunicação, mas uma teoria dos jogos, que inclua a agonística em seus pressupostos" (Ibid., p. 30).

Além do que, esse novo referencial da linguagem na abordagem do saber contemporâneo pós-moderno se distingue da linguagem na Modernidade, que era burocrática e castradora dos lances lingüísticos. Nas palavras de Lyotard: "Esta 'atomização' do social em flexíveis redes de jogos de linguagem pode parecer bem afastada de uma realidade moderna que se representa antes bloqueada pela artrose burocrática" (Ibid., p. 31).

Lyotard inicia a análise da pragmática do saber narrativo apresentando duas objeções já formuladas à aceitação acrítica do conceito instrumental do saber nas sociedades mais desenvolvidas: o saber não se reduz à ciência e esta não esconde o problema de sua legitimidade. Em seguida, o autor define a natureza do saber narrativo, o que permitirá um exame comparativo com as características do saber científico na sociedade contemporânea e sua legitimidade. (Ibid., p. 35). 
Vimos que, ao definir o saber em geral, Lyotard deixa claro que este saber não se reduz à ciência e nem mesmo ao conhecimento como conjunto de enunciados denotativos ou descritivos que podem ser declarados verdadeiros ou falsos. A ciência, por sua vez, seria um subconjunto do conhecimento. No entanto, o conceito de saber é mais amplo: uma mistura de 'idéias de saber-fazer, saber-viver, de saber-escutar'. Trata-se de um conjunto de competências que se encontra além das preocupações com o critério único de verdade, pois se estende aos "critérios de eficiência (qualificação técnica), de justiça e/ou de felicidade (sabedoria ética), de beleza sonora, cromática (sensibilidade auditiva, visual), etc." (Ibid., p. 36). Saber, portanto, coincide com 'formação' de competências.

Já na formulação do saber tradicional prevalece a forma narrativa que tem no relato a sua composição por excelência, e, diversamente das formas desenvolvidas dos discursos de saber, admite nela mesma uma pluralidade de jogos de linguagem. A narrativa da transmissão dos relatos obedece às regras fixadas pela pragmática:

a tradição dos relatos é ao mesmo tempo a dos critérios que definem uma tríplice competência - saber-dizer, saber-ouvir, saber-fazer em que se exercem as relações da comunidade consigo mesma e com o que a cerca. $O$ que se transmite com os relatos é o grupo de regras pragmáticas que constitui o vínculo social (Ibid, p. 40). (Grifo nosso).

Enquanto a pragmática da narrativa popular é auto legitimante, a legitimidade é um jogo de linguagem ocidental que tem como referente o jogo interrogativo por intermédio dos relatos que, por sua vez, determinam os critérios de competência e o direito de o quê dizer e fazer na cultura (Ibid., p. 42).

Inicialmente, Lyotard indica cinco propriedades do saber científico clássico: é um jogo de linguagem isolado que exclui outros e que tem como critério de aceitabilidade o valor de verdade; não é mais imediato e partilhado como o saber narrativo, pois se torna profissão e funda instituições, fazendo surgir o problema da relação entre instituição científica e sociedade; no jogo da pesquisa a competência requerida é somente do enunciador; um relato 
científico não é válido sozinho, pois necessita de provas e pode sempre ser ultrapassado por novas descobertas que exigem novas provas; o jogo da ciência pressupõe uma temporalidade diacrônica, ou seja, a produção de novos conhecimentos supõe conhecimentos anteriores que vão se acumulando.

Lyotard lembra que estas propriedades são conhecidas, mas precisam ser relembradas para salientar a diferença entre o saber científico e o narrativo, bem como a importância de ambos:

De início, o paralelismo da ciência com o saber não científico (narrativo) faz compreender, [...], que a existência da primeira é tão necessária quanto a da segunda, e não menos. Uma e outra são formadas por conjuntos de enunciados; estes são 'lances' apresentados por jogadores no quadro das regras gerais; estas regras são específicas de cada saber, e os 'lances', considerados bons aqui ou ali, não podem ser da mesma espécie, salvo por acaso (lbid., p. 48).

$\mathrm{Na}$ pós-modernidade, por um lado, é estabelecida a igualdade em importância dos dois saberes e Lyotard defende que este fato deve trazer alegria e não nostalgia: "Há, apenas, que se admirar com esta variedade de espécies discursivas, [...]. Lamentar-se sobre 'a perda do sentido' na pósmodernidade seria deplorar que o saber não seja mais principalmente narrativo". (Ibid., p. 49). (Grifo nosso).

Por outro lado, é uma inconseqüência derivar o saber científico do saber narrativo. Como se a narrativa contivesse a ciência em estado embrionário (Ibid., p. 49). O fato do discurso narrativo se autolegitimar pela pragmática de sua transmissão, sem necessitar de argumentação e administração de provas, faz que o cientista clássico o classifique como sendo:

selvagem, primitivo, subdesenvolvido, atrasado, alienado, feito de opiniões, de costumes, de autoridade, de preconceitos, de ignorâncias, de ideologias. Os relatos são fábulas, lendas, mitos bons para as mulheres e as crianças. Nos melhores casos, tentar-se-á fazer penetrar a luz neste obscurantismo, civilizar, educar, desenvolver (lbid., p. 49). 
Tal disparidade, segundo o autor, é determinada pelo imperialismo cultural do Ocidente e é comandada pela exigência de legitimação (Ibid., p. 50).

A ciência moderna recorre ao relato narrativo para a sua própria legitimação. $O$ conflito entre o saber científico e a narrativa está presente desde o jogo de linguagem dos Diálogos platônicos, na qual existe uma pragmática da ciência que já inclui a dupla função de pesquisa e ensino. Nos escritos de Platão já estão presentes: a argumentação em busca do consenso, o acordo como resultado de um único referente, a paridade dos participantes, o reconhecimento de que se trata de um jogo, não de um destino, que exclui os que não aceitam suas regras (Ibid., p. 53). Lyotard chama atenção para 0 paradoxo de que o discurso platônico, que inaugura e legitima a ciência, não ser científico. O saber científico, para saber e dizer que é verdadeiro, precisa recorrer ao relato, à narração, que é para a ciência o não-saber. Do contrário, teria que se pressupor a si mesmo, numa petição de princípio.

A ciência moderna traz duas novas questões para a legitimação: como provar a prova e quem decide o que é verdadeiro? A resposta é dada pelo próprio discurso científico:

\begin{abstract}
Desvia-se da busca metafísica de uma prova primeira ou de uma autoridade transcendente, reconhece-se que as condições do verdadeiro, isto é, as regras de jogo da ciência, são imanentes a este jogo, que elas não podem ser estabelecidas de outro modo a não ser no seio de um debate já ele mesmo científico, e que não existe outra prova de que as regras sejam boas, senão o fato delas formarem 0 consenso dos experts (Ibid., p. 54).
\end{abstract}

Essa legitimação científica ocorre por meio dos relatos simultaneamente à emancipação dos burgueses em relação às autoridades tradicionais, sendo também uma legitimação de sua autoridade, e que está em harmonia com a nova atitude científica:

Disto resulta infalivelmente a idéia de progresso; ela não representa outra coisa senão o movimento pelo qual supõe-se que o saber se acumula, mas este movimento estende-se ao novo sujeito sóciopolítico. O povo está em debate consigo mesmo sobre o que é justo e injusto, da mesma maneira que a comunidade dos cientistas sobre o que é verdadeiro e falso; o povo acumula as leis civis, como 
os cientistas acumulam as leis científicas; o povo aperfeiçoa as regras do seu consenso por disposições constitucionais, como os cientistas revisam à luz dos seus conhecimentos produzindo novos 'paradigmas' (Ibid., p. 55).

Dessa forma, a legitimação, que reimplanta o relato como validade do saber, faz surgir duas novas realidades: um herói do conhecimento e um herói da liberdade. Contudo, nem a legitimação tem um único sentido e nem o relato é suficiente para validá-la.

Lyotard apresenta duas grandes versões dos relatos da legitimação do saber e das instituições na Modernidade, um especulativo (filosófico) e outro prático (emancipação política). O primeiro "tem por sujeito a humanidade como herói da liberdade" (Ibid., p. 59), mediante a apropriação do saber científico. $O$ segundo consiste na condução, pelo Estado e pela Universidade humboldiana, do povo iluminado cientificamente rumo ao progresso, num processo emancipatório (Aufklärung), por intermédio da Formação (Bildung) do indivíduo e da Nação. Esses dois grandes relatos de legitimação sofrem

Na sociedade e na cultura contemporânea, sociedade pós-industrial, cultura pós-moderna, a questão da legitimação do saber coloca-se em outros termos. O grande relato perdeu sua credibilidade, seja qual for o modo de unificação que the é conferido: relato especulativo, relato da emancipação, pois eles sofrem um processo de deslegitimação. (Ibid., p. 69)

Para Lyotard, a deslegitimação dos 'metarrelatos' não está totalmente e fundamentalmente explicada nem pelo desenvolvimento da tecnologia no pós-guerra, nem pelas mudanças keynesianas do capital. O componente determinante dessa deslegitimação tem um elemento interno que é a contradição posta pelos jogos de linguagem que são os 'metarrelatos' 8 , eles próprios jogos de linguagem.

Para Lyotard, o marxismo seria também um 'metarrelato' deslegitimado. Quando o partido substituiu a universidade, o proletariado tomou o lugar do povo e da humanidade, e o materialismo dialético foi trocado pelo idealismo especulativo, o resultado foi o autoritarismo do socialismo como 'metarrelato' equivalente da vida do Espírito hegeliano. Contudo, o marxismo 
pode se apresentar também de forma crítica, socialismo como proposta de constituição do sujeito autônomo, no qual o objetivo da ciência é possibilitar ao proletariado os meios de sua emancipação (lbid., p.65- 66).

Aconteceu também a deslegitimação do saber especulativo hegeliano, este contém inerentemente um ceticismo com relação à ciência que, por não ter encontrado legitimidade não é uma ciência verdadeira. Para o dispositivo especulativo essa legitimidade do discurso científico deve ser dada pelo próprio jogo de linguagem especulativo:

\begin{abstract}
Surge assim a idéia de perspectiva que não é distante, pelo menos neste ponto, da dos jogos de linguagem. Tem-se aí um processo de deslegitimação cujo motor é a exigência de legitimação. A 'crise' do saber científico, cujos sinais se multiplicam desde o fim do século XIX, não provém de uma proliferação fortuita das ciências, que seria ela mesma o efeito do progresso das técnicas e da expansão do capitalismo. Ela procede da erosão interna do princípio de legitimação do saber. Esta erosão opera no jogo especulativo, e é ela que, ao afrouxar a trama enciclopédica na qual cada ciência devia encontrar seu lugar, deixa-as se emanciparem (Ibid., p. 71).
\end{abstract}

Dessa forma, na época pós-moderna ocorrem muitas modificações nas delimitações clássicas dos campos científicos: desaparecem disciplinas, os limites das ciências se entrecruzam surgindo novos conhecimentos, a hierarquia especulativa dos conhecimentos é substituída por uma horizontalidade, as faculdades transformam-se em Institutos e a Universidade perde sua função de legitimidade especulativa, reproduzindo mais professores que cientistas (Ibid., p. 72).

Na deslegitimação do dispositivo de emancipação (Aufklärung) está também intrínseco um poder interno de erosão. Se o discurso da ciência não pode ser tido como verdadeiro, porque tudo é um jogo de linguagem, o discurso da emancipação não pode ser verdadeiramente justo, na medida em que é guiado por aquele saber científico. Assim, fica fragilizada a característica principal do dispositivo de emancipação, que é de fundamentar a legitimidade da ciência desvelando a verdade para proporcionar a autonomia ética, social e política aos interlocutores. Quanto a isso, afirma Lyotard 
prescritivo de valor prático, a diferença é a de pertinência, portanto de competência. Nada prova que, se um enunciado que descreve uma realidade é verdadeiro, o enunciado prescritivo, que terá necessariamente por efeito modificá-la, seja justo (Ibid., p. 72).

A divisão da razão em cognitiva e prática ataca, com efeito, a legitimidade do discurso de ciência, mostrando que ele é um jogo de linguagem com regras próprias, mas sem vocação para regulamentar o jogo prático. Tornando-se, então, um jogo de linguagem entre outros.

As principais conseqüências da deslegitimação dos 'metarrelatos' indicadas por Lyotard, são: a ciência não pode mais legitimar a si mesma e nem a outros jogos de linguagem; a disseminação dos jogos de linguagem dissolve o sujeito e torna a linguagem o vínculo social; o fracasso do dispositivo filosófico especulativo moderno como discurso de legitimação e sustentação do projeto emancipatório; a transformação dos sábios em cientistas com um saber fragmentário; a Filosofia especulativa humanista assume o estudo da lógica ou da história das idéias; o surgimento de um pessimismo generalizado, pois ninguém domina todos os jogos de linguagem e não há uma meta-língua universal; a superação do pessimismo positivista por Wittgenstein, investigando os jogos de linguagem em uma nova perspectiva de legitimação diferente do desempenho, característica do mundo pós-moderno onde não há mais nostalgia com o fim dos 'metarrelatos' e nem a crença no futuro como barbárie (Ibid., p. 73-74).

No entanto, alerta Lyotard, há que se levar em consideração a forma de apropriação do capital sobre a deslegitimação das 'grandes narrativas' e a prevalência dos jogos de linguagem. Neste sentido, a pesquisa é direcionada para a obtenção de desempenho. A administração da prova, que antes tinha por referência o estabelecimento da verdade, com a prova da prova, agora pode recorrer à publicação dos meios com os quais foram feitas as provas para serem repetidas, e mesmo assim levar a equívocos. A resposta é dada por meio de técnicas, tendo a eficiência como critério e a otimização das performances como objetivo: "São estes, pois, os jogos cuja pertinência não é nem o verdadeiro, nem o justo, nem o belo, etc., mas o eficiente: um 'lance' técnico é 'bom' quando é bem-sucedido e/ou quando ele despende menos que um outro" (Ibid., p. 80). 
A administração da prova dentro desses parâmetros, afirma Lyotard, é ainda mais acirrada na medida em que a pragmática do saber científico substitui os saberes tradicionais ou revelados: "Portanto, nada de prova e de verificação de enunciados, e nada de verdade, sem dinheiro. Os jogos de linguagem científica vão tornar-se jogos de ricos, onde os mais ricos têm mais chances de ter razão" (Ibid., p. 81). A melhoria das performances e da realização dos produtos é determinada mais pelo desejo de riqueza do que do progresso do saber ${ }^{9}$ onde, diz Lyotard, riqueza, eficiência e verdade se entrecruzam.

Lyotard afirma ainda que a forma como o capitalismo soluciona o problema do crédito para a pesquisa científica é financiando os departamentos de pesquisa nas empresas e criando fundações de pesquisa privadas, estatais ou mistas, que concedem créditos a departamentos universitários, laboratórios de pesquisa ou grupos independentes de pesquisadores, mesmo que seus resultados sejam demorados. O importante é que a pesquisa seja aplicável e rentável: "as normas de organização do trabalho que prevalecem nas empresas penetram nos laboratórios de estudos aplicados [...], os centros de pesquisa 'pura' percebem créditos menores" (Ibid., p. 82).

Em outras palavras, a administração da prova segue agora um outro jogo de linguagem, onde o importante não é a verdade, mas o desempenho e a eficiência. A predominância do critério técnico no saber científico termina influenciando o critério de verdade, que passa a ser o desempenho:

\footnotetext{
O Estado e/ou a empresa abandona o relato de legitimação idealista ou humanista para justificar a nova disputa: no discurso dos financiadores de hoje, a única disputa confiável é o poder. Não se compram cientistas, técnicos e aparelhos para saber a verdade, mas para aumentar o poder (lbid., p. 83).
}

Dessa forma, pode-se afirmar que a pragmática da pesquisa científica pós-moderna faz assomar a invenção de 'lances' novos e de novas regras de jogos de linguagem. Desta maneira, o atual saber científico busca alternativas para a crise do determinismo, que considera a base da legitimação através do desempenho. Este, por sua vez, deve supor um sistema em estado 
estável, para que ocorra um trânsito regular de input/output. Esta é, no entanto, uma leitura positivista pós-moderna, na qual não se resume todo o pensamento da pós-modernidade: "Trata-se em suma de mostrar em alguns casos típicos que a pragmática do saber científico pós-moderno tem, nela mesma, pouca afinidade com a busca do desempenho" (Ibid., p. 99) (Grifo nosso). Ora, nem toda a ciência pós-moderna se desenvolve pelo positivismo da eficiência, mas também pela produção do ininteligível, do paradoxo, da criação de novas regras lingüísticas que compõe a legitimidade da própria ciência ${ }^{10}$.

A ciência pós-moderna também se desenvolve como pesquisa de instabilidade, para além de determinado positivismo: "o traço surpreendente do saber pós-moderno é a imanência a si mesmo, mas explícita, do discurso sobre as regras que o legitimam" (LYOTARD, 1993a, p. 100). (Grifo nosso).

A idéia predominante nas pesquisas científicas pós-modernas não é mais, portanto, a continuidade e a previsão como paradigmas do conhecimento. Agora a preferência é:

\begin{abstract}
pelos indecidíveis, nos limites da precisão do controle, pelos quanta, pelos conflitos de informação não completa, pelos 'fracta', pelas catástrofes, pelos paradoxos paradigmáticos, a ciência pós-moderna torna a teoria de sua própria evolução descontínua, catastrófica, não retificável, paradoxal. Muda o sentido da palavra saber e diz como esta mudança pode se fazer. Produz, não o conhecido, mas o desconhecido. E sugere um modelo de legitimação que não é de modo algum 0 da melhor performance, mas o da diferença compreendida como paralogia (Ibid., p. 107-108) (Grifo nosso).
\end{abstract}

Lyotard constata que no saber científico pós-moderno, a legitimação se dá através da paralogia, da imprevisibilidade e da diferença. Com a descrença nos 'metarrelatos', o desenvolvimento dos jogos de linguagem e o paradigma da paralogia, o discurso científico pós-moderno se autovalida através do pequeno relato e do dissenso. A legitimação do saber excluiu os grandes relatos, o discurso científico pós-moderno não recorre à dialética do Espírito e nem à emancipação da humanidade para a sua validação. 0 'pequeno relato' é agora o referencial por excelência (lbid., p. 111). Contudo, a partir dessas questões pós-modernas é necessário refletir se é possível uma 
legitimação que se utilize apenas da paralogia e se a pragmática científica deve dar ênfase ao dissentimento, na medida em que "o consenso é um horizonte, jamais ele é atingido" (Ibid., p. 112). Assim:

É ao abandono desta crença que hoje se relaciona o declínio dos relatos de legitimação, sejam eles tradicionais ou 'modernos' (emancipação da humanidade, devir da Idéia). É igualmente a perda desta crença que a ideologia do 'sistema' vem simultaneamente suprir por sua pretensão totalizante e exprimir pelo cinismo do seu critério de desempenho (Ibid., p. 118).

Em virtude da complexidade da pragmática social, composta por uma diversidade de enunciados, é impossível determinar antecipadamente um consenso entre eles. É a descrença nessa possibilidade que deslegitimou os 'metarrelatos' e possibilitou o estabelecimento do desempenho como critério por parte do capital.

\section{CONCLUSÃO}

Na investigação de Lyotard, a pós-modernidade se caracteriza pela descrença nos 'metarrelatos' e a conseqüente valorização das pequenas narrativas. Nesse âmbito é também valorizada a influência das informações tecnológicas e das máquinas informacionais do saber, que substituem os especialistas e os políticos nas decisões sociais. Dessa forma, a recusa dos grandes ideais e dos instrumentos políticos e representativos do coletivo, como o entende a tradição da modernidade, abre espaço para a valorização dos movimentos sociais alternativos, que por sua vez, tem grande importância na crise estrutural do capital. A conseqüência maior dessa recusa, tanto num caso como no outro, é a diluição da idéia de coletividade, fazendo assomar as noções de individualidade ou de pequenos grupos.

Quando Lyotard constata a submissão pós-moderna da ciência, que não é mais portadora do conhecimento verdadeiro, ao processo de valorização do capital e de viabilização da formação de competências para o atendimento do sistema, temos também uma forte aproximação com o papel da ciência na 
crise estrutural do capital quando este se insere completamente na necessária aceleração tecnológica que alimenta a produção destrutiva, a forma de produção mais adequada para sua reprodução dentro da crise.

Nesse sentido, arriscamos dizer que a desmistificação do saber científico operada pelo pensamento pós-moderno, por intermédio da deslegitimação das grandes narrativas, está presente na crise estrutural do capital contemporâneo na sua apropriação da ciência como elemento de produção, agora indispensável no contexto da produção destrutiva. É necessário enfatizar que o pensamento pós-moderno, além de reconhecer a deslegitimação da ciência como portadora do discurso verdadeiro, reconhece também sua deslegitimação operada por meio da sua apropriação pelo capital, da disponibilidade da ciência moderna em atender aos interesses do capital. Em outros termos, o pensamento pós-moderno não é completamente acrítico pró-capitalista, como querem alguns de seus críticos.

A questão é: os pós-modernos não referendam a sua crítica na construção da sociedade alternativa socialista, haja vista sua possibilidade de ser totalitária. Ademais, a crítica pós-moderna à ciência como portadora do conhecimento verdadeiro esbarra na proposição dos jogos de linguagem, onde todos os discursos seriam verdadeiros. Lyotard, no entanto, não desconsidera a apropriação do capital sobre a deslegitimação das grandes narrativas e a prevalência dos jogos de linguagem, nos quais a pesquisa é direcionada para o bom desempenho da produção e dos trabalhadores. O autor enfatiza, por exemplo, que a pesquisa científica que recebe maior financiamento é aquela mais aplicável e rentável.

O fim dos grandes ideais das metanarrativas - como o fim unitário da história e do poder cognitivo e centrado do sujeito moderno, o esmaecimento da crença na emancipação progressiva da razão e da liberdade, a descrença na alternativa socialista e na abstração do conceito moderno de humanidade, etc. - encontra ressonância na forma de ser do capital em sua crise estrutural.

Senão, vejamos. Observemos que os grandes ideais da modernidade eram compatíveis com um capital em sua ascendência histórica e em busca de sua expansão territorial, que se apresentava com validade 
universal para estabelecer sua própria legitimidade e realizar seus intuitos de ampliação e acumulação. Diversamente, um capital em crise estrutural que busca sua reprodução pela produção destrutiva só pode favorecer e ser favorecido num mundo fragmentado, de valores efêmeros, marcado pela paralogia e pelo dissentimento. A taxa de utilização decrescente das mercadorias, essencialmente necessária à produção destrutiva, tem a sua expressão nessa instabilidade constitutiva do mundo e do pensamento pósmoderno. Os ideais universais e estáveis da modernidade já não se coadunam com a produção destrutiva baseada na descartabilidade das mercadorias, a qual se alastra pela totalidade social.

Notas:

${ }^{1}$ Pesquisadora do Laboratório de Estudos do Trabalho e Qualificação Profissional LABOR/ UFC; doutora em Educação - UFC; professora Adjunto do Departamento de Filosofia da Universidade Estadual do Ceará - UECE. E-mail: c-marinho2004@ig.com.br;

2 Conforme Lyotard: "Esta lógica do melhor desempenho é, sem dúvida, inconsistente sob muitos aspectos, sobretudo no que se refere à contradição no campo sócio-econômico: ela quer, simultaneamente, menos trabalho (para baixar os custos da produção) e mais trabalho (para aliviar a carga social da população inativa). Mas a incredulidade resultante é tal que não se espera destas contradições uma saída salvadora, como pensava Marx" (LYOTARD, 1993, p. xvii).

${ }^{3}$ Entenda-se aqui paralogia como imprevisibilidade, dissentimento, contrário ao consenso.

4 Um enunciado científico está submetido a essa regra: "um enunciado deve apresentar determinado conjunto de condições para ser reconhecido como científico" (LYOTARD, 1993, p. 12).

5 Três observações sobre os jogos de linguagem: 1- "...suas regras não possuem sua legitimação nelas mesmas, mas constituem objeto de um contrato explícito ou não entre os jogadores (o que não quer dizer todavia que estes as inventem)"; 2- "...na ausência de regras não existe jogo, que uma modificação, por mínima que seja, de uma regra, modifica a natureza do jogo, e que um lance ou um enunciado que não satisfaça as regras, não pertence ao jogo definido por elas"; 3 - "...todo enunciado deve ser considerado como um 'lance' feito num jogo" (LYOTARD, 1993, p. 17).

6 Para Lyotard ocorre uma nova forma de vinculação social: "O si mesmo é pouco mas não está isolado; é tomado numa textura de relações mais complexa e mais móvel do que nunca. Está sempre, seja jovem ou velho, homem ou mulher, rico ou pobre, colocado sobre os 'nós' dos circuitos de comunicação, por ínfimos que sejam. É preferível dizer: colocado nas posições pelas quais passam mensagens de natureza diversa." (LYOTARD, 1993, p. 28). 
7 Os jogos de linguagem é o mínimo de relação exigido para que haja sociedade: "[...] desde antes do seu nascimento, haja vista o nome que lhe é dado, a criança humana já é colocada como referente da história contada por aqueles que a cercam e em relação à qual ela terá mais tarde de se deslocar. Ou mais simplesmente ainda: a questão do vínculo social, enquanto questão, é um jogo de linguagem, o da interrogação, que posiciona imediatamente aquele que a apresenta, aquele a quem ela se dirige, e o referente que ela interroga: esta questão já é assim o vínculo social" (LYOTARD, 1993, p. 29).

8 Para o autor, as explicações pautadas na economia são insuficientes: "Buscas de causalidades como estas são sempre decepcionantes. Supondo-se que se admita uma ou outra destas hipóteses, resta explicar a correlação das tendências referidas com o declínio do poder unificador e legitimador dos grandes relatos da especulação e da emancipação. [...] O impacto que, por um lado, a retomada e a prosperidade capitalista e, por outro, o avanço desconcertante das técnicas podem ter sobre o estatuto do saber é certamente compreensível. Mas é preciso primeiramente resgatar os germes de 'deslegitimação' e de niilismo que eram inerentes aos grandes relatos do século XIX para compreender como a ciência contemporânea podia ser sensível a estes impactos bem antes que eles acontecessem" (LYOTARD, 1993, p. 69-70).

9 "O que se produz ao final do século XVIII, quando da primeira revolução industrial, é a descoberta da recíproca: não há técnica sem riqueza, mas não há riqueza sem técnica. Um dispositivo técnico exige um investimento; mas visto que otimiza a performance à qual é aplicado, pode assim otimizar a mais-valia que resulta desta melhor performance. Basta que esta mais-valia seja realizada, quer dizer, que o produto da performance seja vendido. E podese bloquear o sistema da seguinte maneira: uma parte do produto desta venda é absorvida pelo fundo de pesquisa destinado a melhorar ainda mais a performance. É neste momento preciso que a ciência torna-se uma força de produção, isto é, um momento na circulação do capital. [...] A conjunção 'orgânica' da técnica com o lucro precede a sua junção com a ciência. As técnicas não assumem importâncias no saber contemporâneo senão pela mediação do espírito de desempenho generalizado" (LYOTARD, 1993, p. 81-82).

10 Para Lyotard, a ciência pós-moderna não se caracteriza somente pelo positivismo mas também pela pesquisa da paralogia: "A expansão da ciência não se faz graças ao positivismo da eficiência. É o contrário: trabalhar na prova é pesquisar e inventar o contra-exemplo, isto é, o ininteligível; trabalhar na argumentação é pesquisar o 'paradoxo' e legitimá-lo com novas regras do jogo de raciocínio. Nos dois casos, a eficiência não é visada por si mesma, ela vem por acréscimo, por vezes tarde, quando os financiadores se interessam enfim pelo caso. Mas, o que não pode deixar de vir e voltar com uma nova teoria, uma nova hipótese, um novo enunciado, uma nova observação, é a questão da legitimidade. Pois é a própria ciência que a si mesma levanta esta questão, e não a filosofia à ciência" (LYOTARD, 1993, p. 99-100).

\section{REFERÊNCIAS BIBLIOGRÁFICAS}

LYOTARD, Jean-François. O pós-moderno. Tradução: Ricardo Correia Barbosa. 4. ed. Rio de Janeiro: José Olympio, 1993.

MARINHO, Cristiane M. Pensamento pós-moderno e educação na crise estrutural do capital. Tese de Doutorado. UFC. Fortaleza - Ce, 2008. 